\title{
Research on Functions of Tourism English in Ecological Tourism Development in Qiannanyu Area of Xingtai County
}

\author{
Ran Li \\ Xingtai University, Xingtai, 054001, China
}

Keywords: Tourism English; Xingtai County; Qiannanyu Area; Ecological tourism; Functions

\begin{abstract}
Despite of good tourism development in Qiannanyu Area of Xingtai County, its international popularity still remains to be improved due to limitation of level of tourism English. Based on this situation, this paper mainly carries out a discussion on the functions of tourism English in ecological tourism development in Qiannanyu Area of Xingtai County.
\end{abstract}

\section{Introduction}

The ecological tourism in Qiannanyu Area of Xingtai County has great development in recent years. However, as more and more foreign tourists come to travel in this area, the ecological tourism project in Qiannanyu Area enjoys higher and higher popularity in international society. Now that large quantity of foreign tourists enter into Qiannanyu Area of Xingtai County, the tourism English plays a more and more prominent function. On this basis, in order to further improve good development of tourism, we shall develop the learning of tourism English to cultivate more professional tourism talents and make contributions to tourism development.

\section{Overview of ecological tourism}

Currently, great changes have happened in the form of tourism in international society, and people's tourism activity has changed from simple sightseeing tour to deep-level experience of cultural connotation; instead of giving a hurried and cursory glance in the past, people start to tale holiday-type form of tourism. With the rapid development of China's tourism, except for above forms of tourism, the ecological tourism also attracts more and more attention, and to return to nature and keep in touch with nature becomes a kind of type of tourism which people most expect and feel most ideal. The development of tourism will cause the most direct influence on the construction of ecological civilization. Therefore, we shall greatly develop China's ecological tourism with the help of tide of China's construction of ecological civilization society. The ecological tourism is just to blend into the nature, absorb cultural connotation, and reduce the adverse factors influencing ecological environment caused by people's activities to ensure the sustainability of tourism resource; with the help of the development of ecological tourism, we can combine protection on ecological environment with economic development in this area to promote the development of this area. In order to realize harmonious coexistence of human and ecological environment, we shall carry out relevant activities based on ecological tourism. While people live in the nature, they shall form an organic whole together with the nature; there is mutual influence and action between the nature and people's life, and the tourism departments, tourism personnel, and other social and economic factors have a coordination to realize a virtuous circle of whole ecological system.

\section{Current situation of development of ecological tourism in Qiannanyu Area of Xingtai County}

As a kind of brand-new form of tourism, the ecological tourism is a kind of green tourism which returns to the nature and also the form of sustainable tourism. The ecological tourism in Qiannanyu Area of Xingtai County, Hebei Province fully meets above features, and this area has advantageous geographical position and convenient traffic. As one of 100 agricultural tourism demonstration sites in China, this scenic area is located in Jiangshui Town in the west of Xingtai County and 60km away 
from the downtown of Xingtai; besides, there are two truck railways in this area and it has a suitable distance away from Yunmeng Mountain, valley group, and Baiyun Mountain; the location belongs to the center of main scenic areas in Xingtai County. In the Taihangshan Area of Xingtai County, there are many breathtaking, deep and serene primitive secondary forests. Qiannanyu Area is located in the hinderland of Taihangshan Area, and it is an area with the best greening in Taihangshan Area. With an area of $116 \mathrm{~km}^{2}$, it has more than 80 natural landscapes and human landscape; with picturesque scenery and pleasant climate, this is a good place for sightseeing and taking a summer holiday or vocation. Furthermore, 8,300 mu of chestnut forest, botanical garden, Wanbang orchard, and other parks have been built in Qiannanyu Area, and the rose park planted adds a beautiful color for this scenic area. With beautiful natural landscape and rich atmosphere of humanity, it must become a famous tourist attraction that many tourists long for.

\section{Functions of tourism English in ecological tourism development in Qiannanyu Area of Xingtai County}

\section{To improve tourism workers' quality via learning tourism English}

In terms of learning and popularization of tourism English in Xingtai County, we shall give full consideration to local actual condition, and analyze the tourism culture and geographical knowledge of Qiannanyu Area of Xingtai County; before learning the tourism English, we shall carry out research and analysis on local actual condition; only after we make a comprehensive study on all knowledge, we can show all the knowledge to world people. In this process, the tourism workers not only can learn English language, but also can complete the promotion of tourism knowledge by virtue of tourism propaganda. In the process of tourism propaganda, the tourism English learners shall select suitable way of propaganda, propaganda content, and propaganda wording. In this way, it is able to realize the effective propaganda of ecological tourism of Qiannanyu Area of Xingtai County to maximum degree.

To promote the ecological tourism development in Qiannanyu Area of Xingtai County via enhancing tourism English teaching

In terms of current development trend of tourism English in China, the changes and adjustment are continuously made in tourism English with the tourism development. While ensuring that the students take tourism English learning, the teachers shall also continuously improve their professional quality, and skillfully combine the learning of theoretical knowledge of tourism English with practical application of tourism English knowledge, which can greatly enhance students' growth in their strength; besides, the students can make expansion on this basis to learn the knowledge of other fields. Therefore, it can be known that the students can integrate the tourism English knowledge they have learnt, change them into their own ideology, and then combine with some work skills mastered in the process of tourism work and utilize suitable ways of propaganda to carry out suitable propaganda for ecological tourism in Qiannanyu Area of Xingtai County. In the process of tourism propaganda, it is required to fully show the tourism features so that the foreign tourists can have urgent desire to travel in this area; moreover, the application of tourism English can further promote the development of ecological tourism in Qiannanyu Area of Xingtai County, continuously improve the tourism popularity of this area, and attract more foreign tourists to have a visit and know local social and humanistic features. Nowadays, as the tourism English is further popularized, in order to develop the tourism in this area, to enhance tourism propaganda activity is an extremely important thing; through propaganda, it is able to improve the tourism popularity of Qiannanyu Area of Xingtai County, and attract more tourists to have a visit. It can be seen that the development of ecological tourism in Qiannanyu Area of Xingtai County can be greatly promoted via further improving tourism English teaching. To enhance education and learning work, improve tourism workers' quality and enhance tourism English learning and education can greatly promote tourism development in Qiannanyu Area of Xingtai County. 


\section{To enhance tourism English teaching and promote healthy development of ecological tourism in Qiannanyu Area of Xingtai County}

\section{Current situation of tourism English}

Currently, the institutions of higher learning have generally established the major of tourism English; in the learning process, the students majoring in tourism English shall not only fully master textbook knowledge, but also timely know and learn the development and change of current forms of tourism. Through mastering more tourism-related knowledge, it is able to help students' career development. With the continuous change in social environment, the tourism also continuously adjusts its development direction in order to meet the basic demand and objective demand of the society, thus the students shall also continuously adjust their development direction in the learning process according to the practical demand of social development so as to lay a firm foundation for later work. The continuous adjustment on teaching objective is not only made based on students' desire for knowledge learning, but also made for the purpose of meeting the basic demand of current tourism and tourism English.

\section{Features of tourism English teaching}

Strong practicability: As for tourism English education, the higher vocational institutions advocate oral English education, that is, they focus on cultivating students' English communication skills and English use ability in actual work process; after completing the tourism English learning, the students shall be able to complete the reception on foreign tourists, booking of hotel rooms, and introduction of basic information of scenic spots to tourists; in the traveling process, the students can use professional tourism English to provide basic assistance and service for foreign tourists. Based on this, the students majoring in tourism English in higher vocational institutions shall enhance learning and cultivation of oral ability, and the schools shall also provide more chances for students to communicate with foreign tourists, correctly understand the meaning of tourism documents, improve the service quality of tourism guidance, and then complete the service work of all tourism projects in a better way.

High skill requirement

In order to engage in foreign affairs-concerned English tour guide or service management of higher hotels after graduation, many students select the major of tourism English, and the learning purpose of this major is to carry out direct communication with foreign people on the basis of sufficient reserve of English knowledge, which lays a firm foundation for their future work and learning.

\section{Strong specialty}

In the learning process, the students majoring in tourism English must master some English vocabulary, sentence patterns and grammar related to foreign affairs-concerned tourism, and can use English to fluently communicate with foreign tourists. Different from learning of other basic English, the tourism English teaching is a professional English teaching work, thus the English learning and training must be systematic and standardized. The students shall skillfully master the relevant process for a tour guide to carry out work, tourism-related laws and regulations, and local cooking culture and humanity features, master basic etiquette of international association, reserve certain international knowledge, and be familiar with tourism safety, world geography, and other professional knowledge.

\section{Reform of tourism English teaching}

To enhance the cultivation of oral communicative ability

In the process of actual English learning, the teachers shall emphasize the practice of oral English and require that the students can completely and fluently express the textbook knowledge via English. Furthermore, the teachers shall set corresponding oral English communicative scenes and let students have free English communication under the set background to enhance students' oral ability and improve students' comprehensive quality.

To use common and descriptive vocabulary

Most of foreign tourists come to travel for the purpose of knowing local customs and cultural features, and they often visit the natural scenery with a relaxed mood; therefore, the tourism workers 
shall use straightaway language to introduce relevant scenic spots and humanistic features so that the tourists can easily and intuitively know relevant information. In the actual work process, the descriptive vocabularies will be massively used, for those vocabularies can enhance tourists' imagination and deepen tourists' impression. Certainly, as for the communication problem caused by local cultural difference, the tourism workers shall select suitable vocabularies to express their information and provide foreign tourists with better tourism service.

To improve the input and output of tourism culture background

While the tourism work is implemented, English shall not only have certain language feature, but also undertake certain responsibility of cultural transmission. Therefore, in the daily teaching work and textbooks, it is required to add more teaching related to Chinese history, culture, and folk customs so that the tourism workers can show local folk customers to world people in a good image in the actual work process. The tourism workers are the messengers of cultural transmission; therefore, to improve relevant personnel's English expression ability, especially oral expression ability, can greatly help the development of whole tourism.

To improve the relation between English teaching and tourism

We shall combine daily teaching work of schools with tourism development in Qiannanyu Area of Xingtai County, provide learners with more chances of field internship, and then combine with local cultural features to carry out practice of oral English and perfect the knowledge reserve of tourism English. In the actual internship process, the learners can also timely find their defects and insufficiencies, and correct and perfect them. In this way, it is able to greatly improve tourism workers' quality and help students to complete their career planning in learning period so as to promote the further development of ecological tourism in Qiannanyu Area of Xingtai County.

\section{Conclusion}

In conclusion, with increasingly frequent international association, the ecological tourism in Qiannanyu Area of Xingtai County shall also seize the development chance to introduce local featured scenic spots to the world and improve local popularity. However, the improvement in popularity of featured scenic spots can't be separated from tourism English, can't be separated from tourism English education, and can't be separated from tourism workers who have skillfully mastered the knowledge of tourism English. Therefore, under the condition of rapid development of ecological tourism in Qiannanyu Area of Xingtai County, the wide workers shall fully know the important promotion function of tourism English on tourism, and the college managers shall also fully know the important significance of cultivating professional tourism English talents so as to practically cultivate a batch of talents with high professional skills and high quality and add more vigor for the development of ecological tourism in Qiannanyu Area of Xingtai County through joint efforts of college tourism English teaching and tourist spots.

\section{Acknowledgments}

This paper is a project of year 2014; the project name is Research on Functions of Tourism English in Ecological Tourism Development in Qiannanyu Area of Xingtai County, and the project number is MSJD2014KT034.

\section{References}

[1] Zhang Xiaoyan: Optimal Construction and Practice of Tourism English Major Curriculum System in Vocational Colleges, Time Education, 2010, (10): 143-144.

[2] Tao Jing: Discussion on Sustainable Development of China's Ecological Tourism, Special Zone Economy, 2011, (01): 176. 
[3] Feng Dingni, Sun Zhi: Language Function of Tourism English and Construction of International First-tier Tourism City of Dalian, Journal of Dalian Maritime University, 2011, 10 (1): 356-357.

[4] Ma Aijun, Liu Hao: Low-carbon Tourism: New Mode of Tourism Development of Ecological Cyclic Economy in Xingtai, Economic Research, 2012, 11 (5): 16. 